\section{Transcription factories are nuclear subcompartments that remain in the absence of transcription}

\author{
Jennifer A. Mitchell and Peter Fraser ${ }^{1}$ \\ Laboratory of Chromatin and Gene Expression, The Babraham \\ Institute, Cambridge CB22 3AT, United Kingdom
}

Nascent transcription occurs at nuclear foci of concentrated, hyperphosphorylated RNA polymerase II (RNAPII). We investigate RNAPII localization, distal gene coassociation, and $\boldsymbol{H} \boldsymbol{b} \boldsymbol{b}$ locus conformation during inhibition of transcription. Our results show distal active genes remain associated with RNAPII foci and each other in the absence of elongation. When initiation is inhibited, active genes dissociate from RNAPII foci and each other, suggesting initiation is necessary to tether distal active genes to shared foci. In the absence of transcription RNAPII foci remain, indicating they are not simple accumulations of RNAPII on transcribed genes but exist as independent nuclear subcompartments.

Supplemental material is available at http://www.genesdev.org.

Received August 23, 2007; revised version accepted

November 1, 2007.

Transcription is a fundamental, life-essential process, yet we lack a clear picture of how and where it occurs in vivo. Textbooks tell us that RNA polymerase II (RNAPII) is recruited to the promoters of genes when they become active, suggesting that transcription sites form de novo on individual genes. However, nascent transcription in the nucleus occurs within a limited number of discrete foci containing high concentrations of active RNAPII, termed transcription factories (Jackson et al. 1993; Wansink et al. 1993). Previously, we showed that the $H b b$ genes are often transcribed in the same factory as other erythroid expressed genes, separated by tens of megabases in cis (Eraf and Uros) or in trans (Hba) (Osborne et al. 2004). This has been confirmed by recent 4C (chromosome conformation capture-on-chip) studies showing associations between $\mathrm{Hbb}$ and multiple active genes (Simonis et al. 2006). Furthermore, several studies have shown that individual genes often loop out of their chromosomal territory upon activation, suggesting repositioning commonly occurs with transcriptional activation (Volpi et al. 2000; Chambeyron and Bickmore 2004; Wiblin et al. 2005). Indeed, we showed recently that immediate early gene activation occurs via rapid gene repositioning to preassembled transcription factories/Os-

[Keywords: RNA polymerase II; nuclear organization; fluorescence in situ hybridization; locus control region; chromosome conformation capture]

${ }^{1}$ Corresponding author.

E-MAIL Peter.Fraser@bbsrc.ac.uk; FAX 44-1223-496022.

Article is online at http://www.genesdev.org/cgi/doi/10.1101/gad.454008. borne et al. 2007). Taken together, these data suggest that genes migrate to pre-existing specialized sites in the nucleus for transcription.

However, whether transcription factories are simply aggregates of RNAPII on individual active genes or independent structures is still unclear. In this study we assessed RNAPII localization during short-term transcription inhibition to investigate these possibilities. DRB (5,6-Dichlorobenzimidazole 1- $\beta$-D-ribofuranoside) specifically inhibits RNAPII elongation by inhibiting kinases that phosphorylate Ser2 of the C-terminal domain (CTD) of the large subunit of RNAPII (Fraser et al. 1978; Marshall and Price 1995; Marshall et al. 1996; Gribnau et al. 1998). Heat shock at $45^{\circ} \mathrm{C}$ has been shown to globally inhibit transcription, disrupting both initiation and elongation (Hieda et al. 2005). In mammalian cells, heatshock-induced inhibition of RNAPII occurs specifically through production of B2 RNAs (transcribed from short interspersed elements [SINEs] by RNA polymerase III) that bind to RNAPII preinitiation complexes, preventing association with promoter DNA (Allen et al. 2004; Espinoza et al. 2007). Long treatments with RNAPII transcription inhibitors lead to disruption of nucleolar structure, chromatin decondenzation, and changes in chromosome territory architecture (Scheer et al. 1984; Davis et al. 1993; Haaf and Ward 1996), suggesting that ongoing transcription maintains nuclear substructures (Cook 2002).

Here we used short treatments with DRB or heat shock to inhibit elongation or initiation, respectively. Our results indicate that transcription factories are not simply aggregates of RNAPII assembling on active genes, but exist as independent subnuclear compartments.

\section{Results and Discussion \\ Transcription inhibition by DRB and heat-shock treatments}

Pulsed fluorouridine (FUrd) incorporation into nascent RNA was used to monitor global transcriptional activity before and after treatment of mouse fetal liver cells that are $60 \%-80 \%$ erythroid (Fig. 1A). FUrd incorporation in untreated cells occurs in hundreds of discrete nucleoplasmic foci and more intense, globular, nucleolar signals in agreement with earlier studies on nascent RNA production. In $99 \%$ of the DRB-treated cells the vast majority of nucleoplasmic foci are no longer apparent, while the intense, nucleolar signals remain. These results are consistent with an effective block to RNAPII elongation. During heat shock, FUrd incorporation was not detected in $84 \%$ of cells, indicating that nascent transcription was effectively inhibited. A small percentage of heat-shocked cells showed low-level FUrd incorporation either in weak nucleolar foci $(13 \%)$ or weak nucleoplasmic foci (2.6\%). DRB-treated and heat-shocked cells were able to recover nascent transcription within $15 \mathrm{~min}$ at $37^{\circ} \mathrm{C}$, confirming that the transcriptional machinery is not permanently damaged by the treatments (Supplemental Fig. 1).

To verify transcriptional inhibition of a specific gene we monitored the highly expressed $H b b-b 1$ gene by RNA FISH (Fig. 1B). Consistent with our earlier work (Gribnau et al. 1998), the RNAPII elongation inhibitor DRB pro- 


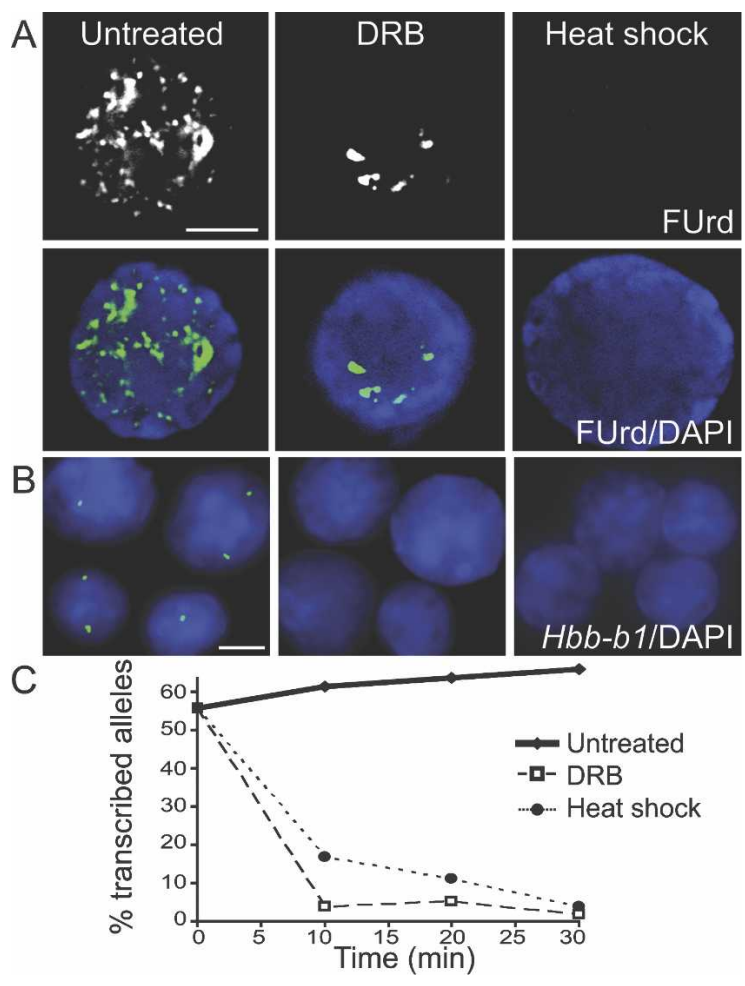

Figure 1. DRB and heat-shock treatment of fetal liver cells inhibits transcription. (A) FUrd incorporation into nascent transcripts in untreated and DRB- and heat-shock-treated fetal liver cells. (Top panel) FUrd immunostaining. (Bottom panel) Overlay of FUrd (green) and DAPI (blue; bar, $4 \mu \mathrm{m}) .(B) H b b-b 1$ RNA FISH signals (green) in untreated and DRB- and heat-shock-treated fetal liver nuclei. DAPI is in blue (bar, $4 \mu \mathrm{m}) .(C)$ Percent transcribed $H b b$-b1 alleles at 0,10 , 20 , and $30 \mathrm{~min}(n>100)$.

duced a dramatic reduction in the number of $H b b-b 1$ RNA FISH signals within 10 min (Fig. 1C). Inhibition of transcription by heat shock also induced a dramatic reduction in the number of $H b b-b 1$ RNA FISH signals within 10 min, with maximal reduction observed at 30 min (Fig. 1C).

\section{Transcription factories remain in the absence of transcription}

We next compared the subnuclear localization of RNAPII by immunofluorescence in untreated, DRBtreated, or heat-shocked cells. We used two different antibodies raised against the initiating form of RNAPII, phosphorylated on Ser5 of the CTD. In both cases we observed a punctate localization of RNAPII that was preserved under conditions of effective transcription inhibition (Fig. 2A). Quantification of the average number of RNAPII foci per optical section revealed no differences in factory numbers between untreated, DRB-, and heatshock-treated cells $(P=0.579)$ (Fig. 2B). These results show that transcription inhibition does not disrupt the focal appearance of the active form of RNAPII or the number of foci detected, suggesting that transcription factories are stable in the absence of transcription. Previous photo-bleaching experiments with GFP-tagged RNAPII identified at least two populations in the nucleus (Kimura et al. 2002): a highly mobile fraction that appeared to be largely inactive, and a relatively immobile fraction engaged in transcription. The immobile fraction was partially decreased by DRB and further reduced by heat-shock treatment, consistent with blocks to elongation and initiation, respectively (Hieda et al. 2005). The fact that focal localization of RNAPII persists after heat shock, in combination with the results of Hieda et al. (2005), suggest that RNAPII in factories may be more rapidly exchanging with the nucleoplasmic pool during heat shock.

To support the finding that the active form of RNAPII was still present in transcription inhibited cells we assessed the soluble and insoluble fractions of RNAPII in unfixed cells. Previous studies have shown that the active, hyperphosphorylated form of RNAPII (RNAPII ${ }_{\mathrm{O}}$ ) resists extraction with saponin, whereas the inactive hypophosphorylated form of RNAPII $\left(\mathrm{RNAPII}_{\mathrm{A}}\right)$ is soluble (Kimura et al. 1999). We compared the soluble and saponin-resistant fractions of RNAPII in untreated, DRB-, and heat-shock-treated fetal liver cells by Western blot (Fig. 2C). In untreated cells $1 \%$ saponin extracts only the inactive $\mathrm{RNAPII}_{\mathrm{A}}$ while $\mathrm{RNAPII}_{\mathrm{O}}$ remains in the saponin-resistant pellet in agreement with previous results. Similarly, in cells treated with DRB or heat shock, saponin extracts only RNAPII $_{\mathrm{A}}$ while RNAPII $_{\mathrm{O}}$ remains in the pellet. Thus, in both cases of transcription inhibition a significant portion of RNAPII remains in the insoluble pellet fraction, supporting our immunofluorescence data showing that Ser5 phosphorylated RNAPII remains in nuclear foci in the absence of transcription.

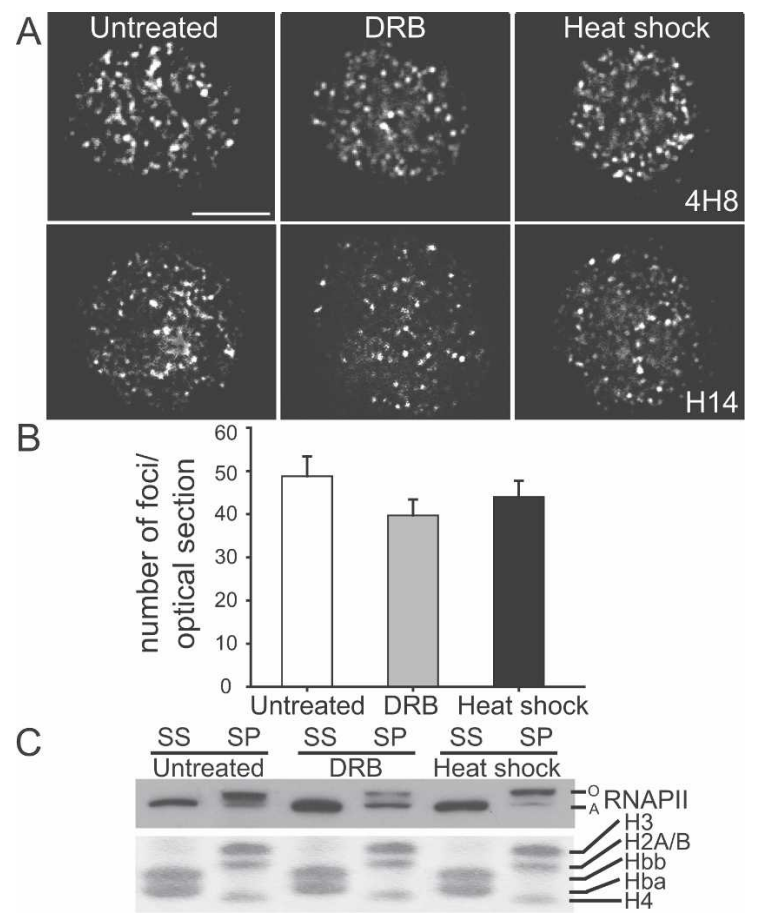

Figure 2. Punctate localization of RNAPII is maintained in the absence of transcription. (A) Immunofluorescence of RNAPII in untreated and DRB- and heat-shock-treated fetal liver nuclei $4 \mathrm{H} 8$ or H14 antibody; bar, $4 \mu \mathrm{m})$. (B) Average number of foci per optical section (4H8) in untreated and DRB- and heat-shock-treated nuclei ( $n>45 ; P=0.5828$; error bars depict SEM). (C) RNAPII was detected by Western in the saponin supernatant (SS) and pellet (SP) using the ARNA-3 antibody. Coomassie staining of histones, retained in the pellet, and globin proteins, extracted by $1 \%$ saponin, shows equal loading. 
Others have shown that disruption of $\beta$-actin, Nuclear Myosin I, or Lamin affect transcription, and have suggested that these factors may have a role in linking the transcriptional machinery to a nuclear scaffold (PesticDragovich et al. 2000; Spann et al. 2002; Hofmann et al. 2004). Our data showing persistence of Ser5 phosphorylated RNAPII foci and a significant saponin-resistant RNAPII $_{\mathrm{O}}$ fraction in the absence of transcription suggest two alternate possibilities. Either RNAPII $_{\mathrm{O}}$ remains associated with genes in the absence of transcription or the RNAPII $_{O}$ is associated with nuclear structures as suggested above. To test this we investigated gene association with RNAPII foci by DNA immuno-FISH and RNAPII binding to genes by chromatin immunoprecipitation (ChIP).

\section{Genes partially dissociate from transcription factories during inhibition of transcription initiation}

We showed previously that transcribed alleles are positioned at RNAPII foci while nontranscribed alleles are positioned away from RNAPII foci (Osborne et al. 2004, 2007). To determine whether previously active alleles remain associated with transcription factories during transcription inhibition we used DNA immuno-FISH to assess association of $\mathrm{Hbb}$ and Eraf with RNAPII foci. In untreated fetal liver we find $60 \%$ of $\mathrm{Hbb}$ alleles are associated with RNAPII foci (Fig. 3A,B), consistent with the RNA FISH data (Fig. 1C) and the percentage of erythroid cells. In DRB-treated cells $62 \%$ of $\mathrm{Hbb}$ alleles are associated with RNAPII foci (Fig. 3A,B), indicating the elongation block does not disrupt genes association with

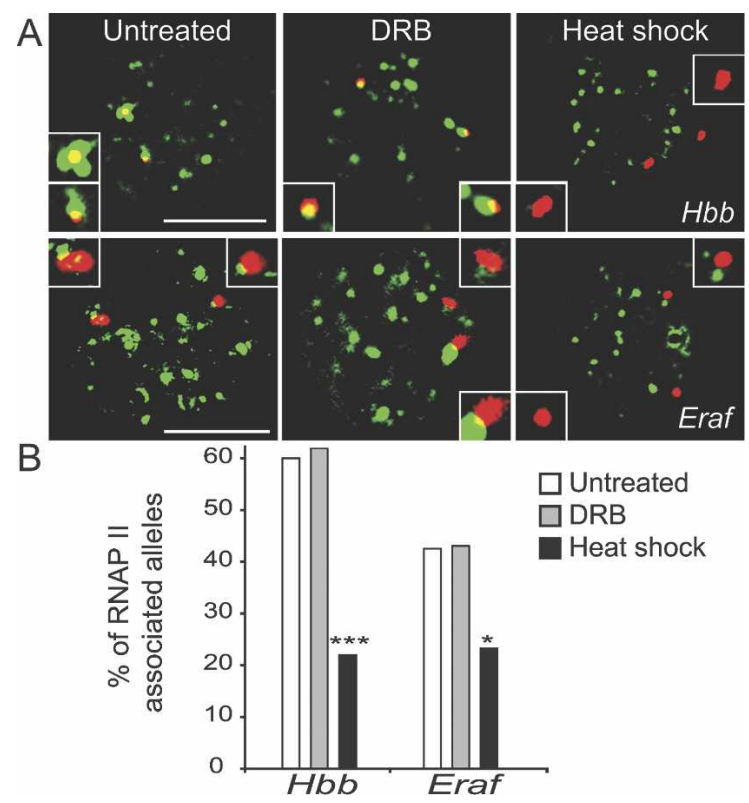

Figure 3. Heat-shock but not DRB treatment causes gene dissociation from RNAPII foci. (A) DNA immuno-FISH, $\mathrm{Hb} b$, or Eraf loci (red) and RNAPII protein (green, 4H8) in untreated and DRB- and heat-shock-treated fetal liver nuclei (bar, $4 \mu \mathrm{m})$. Inset shows a higher magnification of each DNA FISH signal. Representative examples of nuclei showing two alleles colocalizing with RNAPII foci in untreated and DRB-treated nuclei or two dissociated alleles in heatshock-treated nuclei. ( $B$ ) Quantification of RNAPII-associated $\mathrm{Hbb}$ or Eraf alleles by DNA immuno-FISH in untreated and DRB- and heat-shock-treated nuclei $\left.\left.\left(n>40 ;{ }^{\star}\right] P<0.05 ;{ }^{\star \star \star \star}\right] P<0.001\right)$. transcription factories. Conversely, in heat-shocktreated nuclei (Fig. 3A,B) the majority of $\mathrm{Hbb}$ loci are no longer associated with RNAPII foci. These results show that initiation inhibition results in a significant dissociation of previously active $H b b$ alleles from transcription factories $(P=0.000033)$. In the case of Eraf, $43 \%$ of alleles are associated with factories in untreated cells (Fig. 3A,B), reflecting the lower transcriptional frequency of the Eraf gene (Osborne et al. 2004). We found no change in Eraf factory occupancy in DRB-treated nuclei (Fig. 3A,B). However, under conditions of heat shock we found a significant dissociation from factories $(P=0.035)$ (Fig. 3A,B).

To provide further evidence that many erythroid expressed genes dissociate from active RNAPII during transcription inhibition we performed ChIP with an antibody specific for Ser5 phosphorylated RNAPII (Supplemental Fig. 2). The ChIP results show a dramatic reduction in RNAPII occupancy at erythroid expressed genes (Hba, Hbb-b1, Slc4a1, Eraf) after heat-shock treatment, confirming that Ser5 phosphorylated RNAPII largely dissociates from active genes. DRB treatment also leads to a reduction in RNAPII occupancy, which was most apparent at the $3^{\prime}$ end of $H b b-b 1$ and Slc4a1, consistent with an elongation block. Although our results do not show that all previously expressed genes dissociate from transcription factories nor a complete absence of RNAPII on previously active genes, our data are most consistent with the idea previously proposed by others that transcription factories are tethered to a nuclear structure and are not simply aggregates of RNAPII on active genes.

\section{Transcription initiation is required \\ for distal gene coassociation}

We previously showed that distal transcribed genes often share the same transcription factory (Osborne et al. 2004). If transcription factories are merely the result of aggregates of RNAPII on active genes, and the association of distal active genes is due to chance colocalization, then inhibition of transcription should not affect long-range gene associations. If, on the other hand, colocalization of distal genes is dependent on transcription because active genes migrate to shared subcompartments, then inhibition of transcription should result in the dissociation of distal genes. To test these possibilities we used the $3 \mathrm{C}$ assay to monitor associations between distal expressed genes $H b b-b 1$ and Eraf (25 Mb apart) as well as Eraf and Uros (5 Mb apart) on chromosome 7 . The $3 \mathrm{C}$ results (Fig. 4A) show that gene coassociations are unaffected by elongation inhibition, in agreement with our DNA immuno-FISH data showing that these genes remain associated with factories. However, during inhibition of initiation $3 \mathrm{C}$ products are no longer detected, indicating associations between $H b b-b 1$ and Eraf are disrupted. Similarly, the Eraf and Uros 3C products are absent during heat shock. These results show associations between these distal genes are dependent on the process of transcription, and that coassociation with a shared transcription factory is required.

The Hbb active chromatin hub (ACH) is maintained in the absence of transcription

The $\mathrm{Hbb} \mathrm{ACH}$ involves close association between the active $H b b$ genes and distal hypersensitive sites (HS) of 


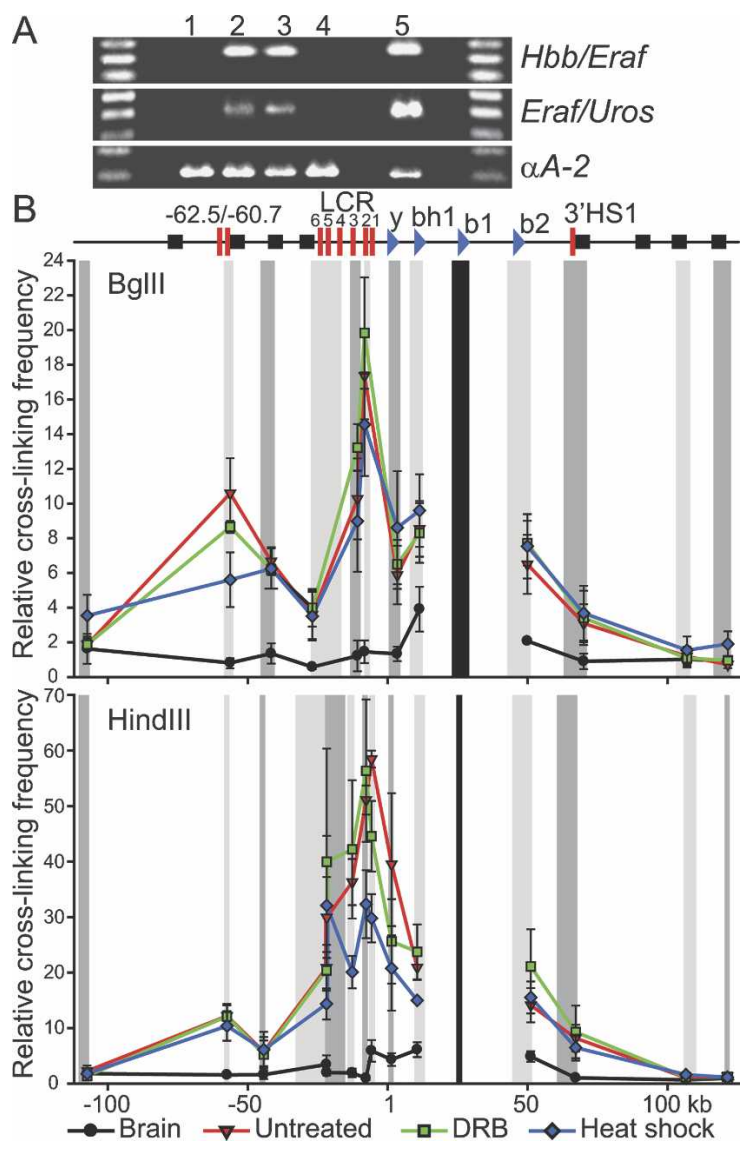

Figure 4. Heat-shock but not DRB treatment causes dissociation of distal-clustered genes while $H b b$ locus conformation is largely maintained. (A) 3C interactions in fetal brain (1) and untreated (2), DRB-treated (3), and heat-shock-treated (4) fetal liver cells. 3C control template (5). (C) $3 \mathrm{C}$ interactions across the $\mathrm{Hbb}$ locus relative to $H b b-b 1$ (black bar). Chromatin digested with BglII or HindIII. Relative cross-linking frequency determined at each point for the restriction fragments indicated in gray (adjacent fragments in alternating intensities) normalized to that of the most 3 ' fragment. A schematic of the $\mathrm{Hbb}$ locus indicates the position of the globin genes (blue sideways triangles), HS (red bars), and olfactory receptor genes (black squares). Error bars depict SEM $(n=3)$.

the $\mathrm{Hbb}$ locus control region (LCR) (Carter et al. 2002; Tolhuis et al. 2002). To determine the effects of transcription inhibition on ACH structure we conducted 3C assays with fetal brain, and untreated, DRB-, and heatshock-treated fetal liver cells. In untreated cells we observed a profile of interactions between the active $H b b-b 1$ gene and the LCR that is not observed in the fetal brain (Fig. 4B), in agreement with previous studies (Tolhuis et al. 2002; Palstra et al. 2003). When either BglII or HindIII was used for digestion in the 3C assay, fetal liver-specific interactions were highest throughout the LCR. The most dramatic interaction was seen in the region of HS2 using HindIII, which separates HS2 from the other HS in the LCR (30- to 50-fold increased ligation frequency compared to the fetal brain). Strikingly, no significant changes in cross-linking frequency are observed under both conditions of transcription inhibition in the BglII profile $(P=0.693)$. Digestion with HindIII separates the $H b b-b 1$ promoter from the $3^{\prime}$ end of the $H b b-b 1$ gene, while in the case of BglII the entire $H b b-b 1$ gene lies in a larger restriction fragment. In the HindIII profile ACH conformation is largely maintained in fetal liver cells, showing significantly higher cross-linking frequency across the locus when compared with the brain $(P<0.001)$. However, a significant disruption in the interactions of $\mathrm{Hbb}-b 1$ with HS2 and HS3 of the LCR was observed in heat-shock treatment compared to both untreated $(P=0.014, P=0.033)$ and DRB-treated $(P=0.002$, $P=0.004$ ) cells, suggesting there may be increased mobility in this region under conditions of heat-shock inhibition of transcription.

Functional studies in knockout mice have shown that the LCR is required for high level expression of the linked $\mathrm{Hbb}$ genes (Epner et al. 1998; Bender et al. 2000), with HS2 having the greatest effect on transcription of the $\mathrm{Hbb}$ genes (Fiering et al. 1995). Our data are consistent with the HS2/3 region having a specific role in transcription initiation via close contact with the Hbb-b1 promoter. Promoter-HS2 contacts are disrupted during initiation inhibition while the overall erythroid-specific conformation of the $\mathrm{ACH}$ is maintained. Collectively, our data reveal the $\mathrm{ACH}$ is largely maintained in the absence of transcription and when most alleles are dissociated from RNAPII foci, indicating that the $\mathrm{ACH}$ is distinct from transcription factories. Furthermore, unlike the association of distal genes in transcription factories, ACH conformation is not dependent on the process of transcription, and may poise the locus for transcription factory association (Fraser and Engel 2006; Ragoczy et al. 2006).

\section{Conclusions}

We showed transcription factories are maintained in the absence of transcription and reduced gene occupancy (model shown in Fig. 5). Inhibition of initiation causes gene dissociation from RNAPII foci and multimegabase associations between active genes are lost. Conversely, under conditions of elongation inhibition, initiating genes remain associated with RNAPII foci and maintain long-range associations with distal genes. These results show that associations between distal genes are transcription-dependent and require coassociation with a shared transcription factory. Previous reports have provided evidence that the transcription machinery may be associated with a nuclear scaffold structure (Jackson and Cook 1985; Vincent et al. 1996; Kimura et al. 1999; Pestic-Dragovich et al. 2000; Spann et al. 2002; Hofmann et al. 2004; Vreugde et al. 2006). We showed that under conditions inhibiting both transcription initiation and elongation RNAPII remains associated with the insoluble nuclear fraction, even when highly expressed genes dissociate from RNAPII foci. These results suggest that transcription factories are associated with a nuclear structure rather than being simple aggregations of RNAPII on active genes. Our data also show that chromatin loop structures are distinct from transcription factories, and suggest that chromatin hub structures are not nucleation sites for transcription factories. These structures may form prior to entering a factory, and could poise genes for association with a factory or stabilize their presence there (Fraser and Engel 2006; Ragoczy et al. 2006). It remains to be determined what specific factors hold transcription factory structures together and whether gene association with factories occurs via active recruitment or passive diffusion. In conclusion, our data show that transcription factories are distinct subnuclear 


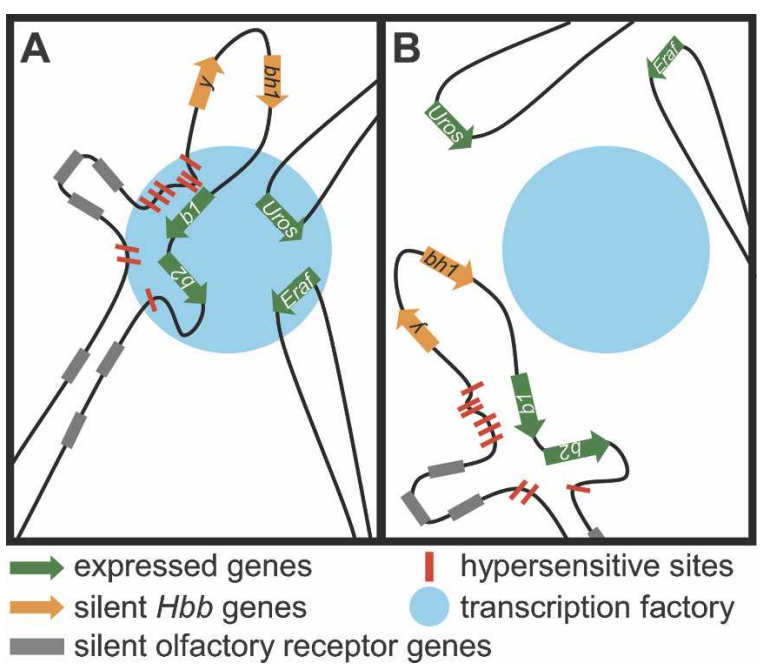

Figure 5. Model of gene occupancy in transcription factories in the presence and absence of transcription. (A) Expressed genes, $H b b-b 1$, b2, Eraf, and Uros (green arrows) dynamically associate with transcription factories (blue circle) when transcribed and often coassociate in a shared factory. The Hbb locus forms chromatin loops, HS (red bars) of the LCR are in close contact with transcribed $H b b$ genes (contact with $\mathrm{Hbb}$-b1 depicted). HS2 and HS3 form a tighter association with the $H b b-b 1$ promoter during transcription initiation, possibly through transcription factor-RNAPII interactions. This conformation of the $\mathrm{Hbb}$ locus and gene association with transcription factories occurs during initiation and is maintained in the absence of elongation. $(B)$ In the absence of transcription initiation, previously active genes dissociate from transcription factories. Conformation of the $\mathrm{Hbb}$ locus is largely maintained; however, there is a disruption in the association of HS2 and HS3 with the Hbb-b1 promoter.

compartments, and suggest that gene relocation to factories is a required step in regulated transcription.

\section{Materials and methods}

Tissue collection and transcription inhibition

Fetal liver or brain was obtained from day 14.5 C57BL/6 embryos, disrupted to a single-cell suspension in ice-cold PBS, and suspended in $37^{\circ} \mathrm{C}$ DMEM containing $10 \%$ FBS at 4 million cells per milliliter. Untreated fetal liver cells were maintained at $37^{\circ} \mathrm{C}$ for the same amount of time as treated cells. Fetal liver cells treated with $50 \mu \mathrm{g} / \mathrm{mL}$ DRB (Sigma-Aldrich) were maintained for $30 \mathrm{~min}$ at $37^{\circ} \mathrm{C}$, unless otherwise indicated. Heatshocked cells were incubated for $30 \mathrm{~min}$ at $45^{\circ} \mathrm{C}$, unless otherwise indicated. Cells were fixed immediately after the incubation period by the appropriate method. All animal experimental procedures were carried out under a project license granted from the Home Office, UK.

RNA FISH and immunofluorescence

RNA FISH and immunofluorescence were performed as described previously (Gribnau et al. 2000); for details, see the Supplemental Material.

\section{DNA immuno-FISH}

DNA FISH was performed as described previously (Brown et al. 2001). BAC clones (195-kb RP24-344M21 for Hbb and 170-kb RPCI-23-353J20 for Eraf) were labeled by nick translation either directly with Alexa Fluor 594 or with biotin and detected with Avidin D-Texas Red. RNAPII was detected after DNA FISH using the 4H8 RNAPII antibody.

Microscopy and image analysis

RNA FISH signals were examined on an Olympus BX41 epifluorescence microscope and representative images were captured on a CCD camera (see the Supplemental Material for details).
Saponin extractions and Western blotting

Saponin extraction was carried out as described previously (Kimura et al. 1999); for details, see the Supplemental Material.

$3 C$ and quantitative $P C R$

The 3C assay was carried out essentially as described in Osborne et al. (2004). See the Supplemental Material for details and modifications.

\section{Statistical analysis}

Statistical differences between groups for RNA and DNA FISH data was determined using a two-tailed Fisher's exact test. A one-way ANOVA was applied to log-transformed data to assess differences between groups in the number of RNAPII foci; no post-test was used as $P>0.05$. 3C data were analyzed by two-way ANOVA. Where appropriate, a contrast test was applied to assess significant differences at specific genomic locations in the $3 \mathrm{C}$ profile. One- and two-way ANOVA were carried out using SPSS 14.0 (SPSS, Inc.).

\section{Acknowledgments}

We thank Drs. A. Corcoran, L. Chakalova, and N. Hawkes for critically reading the manuscript; Dr. A. Segonds-Pichon for statistical support; and members of the Laboratory of Chromatin and Gene Expression for helpful discussions. J.A.M. was supported by a Natural Science and Engineering Research Council of Canada Post-doctoral Fellowship. P.F. is a Senior Fellow of the Medical Research Council, UK. This study was supported in part by the Medical Research Council and the Biotechnology and Biological Sciences Research Council, UK.

\section{References}

Allen, T.A., Von Kaenel, S., Goodrich, J.A., and Kugel, J.F. 2004. The SINE-encoded mouse B2 RNA represses mRNA transcription in response to heat shock. Nat. Struct. Mol. Biol. 11: 816-821.

Bender, M.A., Bulger, M., Close, J., and Groudine, M. 2000. $\beta$-Globin gene switching and DNase I sensitivity of the endogenous $\beta$-globin locus in mice do not require the locus control region. Mol. Cell 5: 387-393.

Brown, K.E., Amoils, S., Horn, J.M., Buckle, V.J., Higgs, D.R., Merkenschlager, M., and Fisher, A.G. 2001. Expression of $\alpha$ - and $\beta$-globin genes occurs within different nuclear domains in haemopoietic cells. Nat. Cell Biol. 3: 602-606.

Carter, D., Chakalova, L., Osborne, C.S., Dai, Y.F., and Fraser, P. 2002. Long-range chromatin regulatory interactions in vivo. Nat. Genet. 32: 623-626.

Chambeyron, S. and Bickmore, W.A. 2004. Chromatin decondensation and nuclear reorganization of the HoxB locus upon induction of transcription. Genes \& Dev. 18: 1119-1130.

Cook, P.R. 2002. Predicting three-dimensional genome structure from transcriptional activity. Nat. Genet. 32: 347-352.

Davis, L., Cadrin, M., Brown, D.L., and Chaly, N. 1993. Reversible disassembly of transcription domains in lymphocyte nuclei during inhibition of RNA synthesis by DRB. Biol. Cell. 78: 163-180.

Epner, E., Reik, A., Cimbora, D., Telling, A., Bender, M.A., Fiering, S., Enver, T., Martin, D.I., Kennedy, M., Keller, G., et al. 1998. The $\beta$-globin LCR is not necessary for an open chromatin structure or developmentally regulated transcription of the native mouse $\beta$-globin locus. Mol. Cell 2: 447-455.

Espinoza, C.A., Goodrich, J.A., and Kugel, J.F. 2007. Characterization of the structure, function, and mechanism of B2 RNA, an ncRNA repressor of RNA polymerase II transcription. RNA 13: 583-596.

Fiering, S., Epner, E., Robinson, K., Zhuang, Y., Telling, A., Hu, M., Martin, D.I., Enver, T., Ley, T.J., and Groudine, M. 1995. Targeted deletion of $5^{\prime}$ HS2 of the murine $\beta$-globin LCR reveals that it is not essential for proper regulation of the $\beta$-globin locus. Genes \& Dev. 9: 2203-2213.

Fraser, P. and Engel, J.D. 2006. Constricting restricted transcription: The (actively?) shrinking web. Genes \& Dev. 20: 1379-1383.

Fraser, N.W., Sehgal, P.B., and Darnell, J.E. 1978. DRB-induced premature termination of late adenovirus transcription. Nature 272: 590593.

Gribnau, J., de Boer, E., Trimborn, T., Wijgerde, M., Milot, E., Grosveld, F., and Fraser, P. 1998. Chromatin interaction mechanism of tran- 
scriptional control in vivo. EMBO J. 17: 6020-6027.

Gribnau, J., Diderich, K., Pruzina, S., Calzolari, R., and Fraser, P. 2000. Intergenic transcription and developmental remodeling of chromatin subdomains in the human $\beta$-globin locus. Mol. Cell 5: 377-386.

Haaf, T. and Ward, D.C. 1996. Inhibition of RNA polymerase II transcription causes chromatin decondensation, loss of nucleolar structure, and dispersion of chromosomal domains. Exp. Cell Res. 224: 163173.

Hieda, M., Winstanley, H., Maini, P., Iborra, F.J., and Cook, P.R. 2005. Different populations of RNA polymerase II in living mammalian cells. Chromosome Res. 13: 135-144.

Hofmann, W.A., Stojilikovic, L., Fuchsova, B., Vargas, G.M., Mavrommatis, E., Philimonenko, V., Kysela, K., Goodrich, J.A., Lessard, J.L., Hope, T.J., et al. 2004. Actin is part of pre-initiation complexes and is necessary for transcription by RNA polymerase II. Nat. Cell Biol. 6: 1094-1101.

Jackson, D.A. and Cook, P.R. 1985. Transcription occurs at a nucleoskeleton. EMBO I. 4: 919-925.

Jackson, D.A., Hassan, A.B., Errington, R.J., and Cook, P.R. 1993. Visualization of focal sites of transcription within human nuclei. EMBO J. 12: 1059-1065.

Kimura, H., Tao, Y., Roeder, R.G., and Cook, P.R. 1999. Quantitation of RNA polymerase II and its transcription factors in an HeLa cell: Little soluble holoenzyme but significant amounts of polymerases attached to the nuclear substructure. Mol. Cell. Biol. 19: 5383-5392.

Kimura, H., Sugaya, K., and Cook, P.R. 2002. The transcription cycle of RNA polymerase II in living cells. J. Cell Biol. 159: 777-782.

Marshall, N.F. and Price, D.H. 1995. Purification of P-TEFb, a transcription factor required for the transition into productive elongation. $J$. Biol. Chem. 270: 12335-12338.

Marshall, N.F., Peng, J., Xie, Z., and Price, D.H. 1996. Control of RNA polymerase II elongation potential by a novel carboxyl-terminal domain kinase. J. Biol. Chem. 271: 27176-27183.

Osborne, C.S., Chakalova, L., Brown, K.E., Carter, D., Horton, A., Debrand, E., Goyenechea, B., Mitchell, J.A., Lopes, S., Reik, W., et al. 2004. Active genes dynamically colocalize to shared sites of ongoing transcription. Nat. Genet. 36: 1065-1071.

Osborne, C.S., Chakalova, L., Mitchell, J.A., Horton, A., Wood, A.L., Bolland, D.J., Corcoran, A.E., and Fraser, P. 2007. Myc dynamically and preferentially relocates to a transcription factory occupied by Igh. PLOS Biol. 5: e192. doi: 10.1371/journal.pbio.0050192.

Palstra, R.J., Tolhuis, B., Splinter, E., Nijmeijer, R., Grosveld, F., and de Laat, W. 2003. The $\beta$-globin nuclear compartment in development and erythroid differentiation. Nat. Genet. 35: 190-194.

Pestic-Dragovich, L., Stojilikovic, L., Philimonenko, A.A., Nowak, G., Ke, Y., Settlage, R.E., Shabanowitz, J., Hunt, D.F., Hozak, P., and de Lanerolle, P. 2000. A myosin I isoform in the nucleus. Science 290: 337-341.

Ragoczy, T., Bender, M.A., Telling, A., Byron, R., and Groudine, M. 2006. The locus control region is required for association of the murine $\beta$-globin locus with engaged transcription factories during erythroid maturation. Genes \& Dev. 20: 1447-1457.

Scheer, U., Hugle, B., Hazan, R., and Rose, K.M. 1984. Drug-induced dispersal of transcribed rRNA genes and transcriptional products: Immunolocalization and silver staining of different nucleolar components in rat cells treated with 5,6-dichloro- $\beta$-D-ribofuranosylbenzimidazole. J. Cell Biol. 99: 672-679.

Simonis, M., Klous, P., Splinter, E., Moshkin, Y., Willemsen, R., de Wit, E., van Steensel, B., and de Laat, W. 2006. Nuclear organization of active and inactive chromatin domains uncovered by chromosome conformation capture-on-chip (4C). Nat. Genet. 38: 1348-1354.

Spann, T.P., Goldman, A.E., Wang, C., Huang, S., and Goldman, R.D. 2002. Alteration of nuclear lamin organization inhibits RNA polymerase II-dependent transcription. J. Cell Biol. 156: 603-608.

Tolhuis, B., Palstra, R.J., Splinter, E., Grosveld, F., and de Laat, W. 2002. Looping and interaction between hypersensitive sites in the active $\beta$-globin locus. Mol. Cell 10: 1453-1465.

Vincent, M., Lauriault, P., Dubois, M.F., Lavoie, S., Bensaude, O., and Chabot, B. 1996. The nuclear matrix protein p255 is a highly phosphorylated form of RNA polymerase II largest subunit which associates with spliceosomes. Nucleic Acids Res. 24: 4649-4652.

Volpi, E.V., Chevret, E., Jones, T., Vatcheva, R., Williamson, J., Beck, S., Campbell, R.D., Goldsworthy, M., Powis, S.H., Ragoussis, J., et al.
2000. Large-scale chromatin organization of the major histocompatibility complex and other regions of human chromosome 6 and its response to interferon in interphase nuclei. J. Cell Sci. 113: 15651576.

Vreugde, S., Ferrai, C., Miluzio, A., Hauben, E., Marchisio, P.C., Crippa, M.P., Bussi, M., and Biffo, S. 2006. Nuclear myosin VI enhances RNA polymerase II-dependent transcription. Mol. Cell 23: 749-755.

Wansink, D.G., Schul, W., van der Kraan, I., van Steensel, B., van Driel, R., and de Jong, L. 1993. Fluorescent labeling of nascent RNA reveals transcription by RNA polymerase II in domains scattered throughout the nucleus. J. Cell Biol. 122: 283-293.

Wiblin, A.E., Cui, W., Clark, A.J., and Bickmore, W.A. 2005. Distinctive nuclear organisation of centromeres and regions involved in pluripotency in human embryonic stem cells. J. Cell Sci. 118: 3861-3868. 


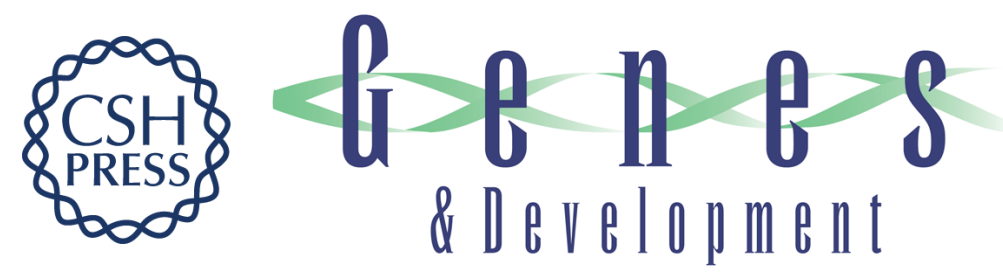

\section{Transcription factories are nuclear subcompartments that remain in the absence of transcription}

Jennifer A. Mitchell and Peter Fraser

Genes Dev. 2008, 22:

Access the most recent version at doi:10.1101/gad.454008

Supplemental
Material http://genesdev.cshlp.org/content/suppl/2007/12/18/22.1.20.DC1

References This article cites 37 articles, 16 of which can be accessed free at: http://genesdev.cshlp.org/content/22/1/20.full.html\#ref-list-1

License

Email Alerting

Receive free email alerts when new articles cite this article - sign up in the box at the top Service right corner of the article or click here.

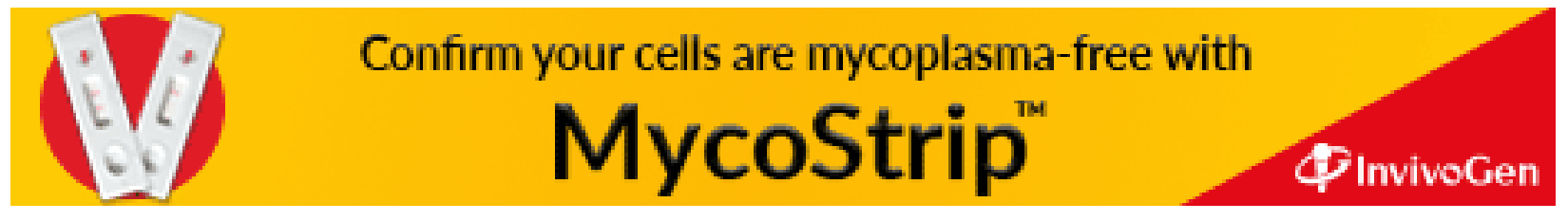

